\title{
The Evolution and Transformation of the Ethno-Geological Systems of the Trans-Ural Forest-Steppe into Civilized Chronotopes
}

\section{O G Zavyalova}

Department of Geography, Fundamental Ecology and Natural Resource Management, Kurgan State University, Kurgan, Russia

\section{Abstract}

The article discusses the results of a post-dissertation doctoral study on the thousandyear evolution of the ethno-geological systems of Trans-Urals forest-steppe based on the ethno-system analysis method of territorial development and the structural ethnocontact principles developed by the author. Geographical factors of the ethno-social organization of the Russian space are an important factor of their cultural and ethnic identity and development of multi-ethnic regions. Territorial structures become trigger mechanisms of many regional processes: ethno-social, economic, environmental, etc.

Corresponding Author:

O G Zavyalova

kaf_bgd@rambler.ru

Received: 25 October 2019

Accepted: 15 November 2019

Published: 25 November 2019

Publishing services provided by

Knowledge $\mathrm{E}$

(c) O G Zavyalova. This article is distributed under the terms of the Creative Commons

Attribution License, which

permits unrestricted use and redistribution provided that the original author and source are credited.

Selection and Peer-review under the responsibility of the AgroSMART 2019 Conference Committee.

\section{G OPEN ACCESS}

The resulting cooperative (synergistic) effects caused by contacts and the similar development institutions significantly influence the emerging territorial structures. Society is to be analyzed as a global ethno-system where the processes of ethnonatural interaction play a basic role. They result the evolution of territorial systems of management of natural resources and economy management. The author proposes a new content of the concept "civilization chronotope" -- "Siberian" as a result of a long-term ethno-cultural transformation of the Southern Trans-Urals ethno-geosystems, ethno-contact zone, a common ethnic and economic co-evolution of the peoples of South-Western Siberia.

Keywords: ethno-geographic system, ethnicity, ethno-contact zone, chronostructure, Siberians chronotopes, Trans-Urals forest-steppe, South-Western Siberia.

\section{Introduction}

Enhancing the inter-ethnic relations need to be studied not only through contradictions in the geography of conflicts, but also through positive results of ethnic contact. Nowadays the phenomenon of cultural and ethnic hybridity is not well studied as the inter-ethnic conflict. Modern geographic research is less focused on the issues of ethnocultural traditions, cultural heterogeneity of territorial systems, as well as and in the natural environment and its territorial features are considered less important in the ecology studies. 
The territory of the Trans-Ural forest-steppe is located in a transitional natural zone, on the forests and steppes, it has been a zone of interaction of many ethnic communities for several thousand years: Finno-Ugric tribes and sargats, Turks and Slavs, hunters and traders, nomadic pastoralists and farmers. The forest-steppe zone of the Southern Trans-Ural is extended by a narrow strip (150--300 km) from the Urals to the Ishim River.

The common frontier with the Republic of Kazakhstan becomes the main issue of the studying the development of ethno-geological systems of the Trans-Ural forest-steppe. The length of the Russian-Kazakh border (one of the longest land borders in the world) is about $6,800 \mathrm{~km}$. It unites 10 constituent entities of the Russian Federation and almost half of the territories of Kazakhstan. Cross-border cooperation of ethno-contact states lead to the re-establishment of a common economic space and the full integration of states and people. This is due to the centuries-old traditions of Western Siberia -- the coexistence of the Turkic, Finno-Ugric and East Slavic ethnicity.

The dialectic synthesis of general geographical structures with ethnic systems represents a particular issue. L.N. Gumilev noted that a systematic approach allows to move from ethnic classification -- the offspring of ethnography, which distinguishes an ethnos on any basis (language, etc.) to ethnic systematics [5]. Geosystem approaches most clearly reflect existing realities. The author of the article developed an algorithm for ethno-system analysis of the forest steppe Trans-Urals based on the integration of system-dynamic, historical-ethnological, innovative-synergetic approaches [6].

The regional approach of the study identifies the spatial-temporal patterns of evolution and transformation, depending on the different types of natural and ethnic environment. But the one-sided analysis of development from the perspectives of the traditional economy is insufficient. It lacks a number of other main properties and characteristics, and many systemic interactions are represented less important. Economic and cultural communities do not reflect the whole complex of interrelations of ethnic communities with the outward and among the community itself.

Nowadays, the ethno-genetic coordinate in the regional development analysis is increasing. Thus, V.P. Alekseev's idea about ethno-genetic beams in space and time correlates with the ideas of S.F. Huntington, J. Willie, and U. Bennet about "common tradition as a comprehensive unity of history and culture", the region "co-tradition ", and "genetic sequence" by L.S. Klein and others [1, 9, 17--19].

The problems of ethno-geological system structuring is solved not only through identification and classification of structures. Soviet scientists discovered the aspects of the combined structuring of territorial systems. P.Ya. Baklanov noted that on the same areas of the territory, multiple intersection of private zones (spaces) is possible, as a 
result of which integral zones of influence of various elements are formed [2]. Improving the functioning of structures mostly occurs by developing and the formation of the missing, reducing of excess elements and relations.

\section{Methods and Materials}

Complex combined structures, such as ethno-contact zones, are formed in the process of functioning and development of various private structures and subsystems as a result of their intersection, overlapping, combining, etc. Compared with the original private structures, the combined structures have qualitatively new properties and features.

Civilizational space-time approach of the analysis becomes an important issue. Day by day the need to supplement the concept of ethno-systemic analysis with modern observations and conclusions grows. The structural complication of territorial social systems occurs as a result of the dynamics and evolution of the corresponding subsystems while maintaining their proportionality, i.e., manifestation of the processes of chronostructuring [16].

Currently, it is extremely important to determine the completeness and balance of all elements of the EHS, their degree of completeness, stability and new transformation qualities.

There is an important issue in the study of ethno-geological system and ethno-contact zone evolution: the criterion of the level and stages of the stages of specific territories need to be identified (in this case, the south of Western Siberia). In particular, the phasing of changes in the regional ethno-social, ethno-cultural and economic organization. Three aspects should be taken into account: orderliness, orientation and balance of systems. Orderliness is quantified, as the reciprocal of the entropy. The focus of the organization characterizes the compliance of the ethno-social development with the environmental conditions, it can be fixed according to the homeostasis of the system, as the degree of inconsistency or contrast.

The concept of ethno-systemic analysis suggested by the author is based on a systemic-dialectic, evolutionary approach. The approaches are put forward to solve the problems as ethno-natural and social interaction, the paradigm of geosystem, space-time and territorial organization of society, the theory of ethnos, systemic and evolutionary dynamics, non-linear oscillations. There is a need to develop an integration of space-time, ethno-systemic and civilizational approaches and methods. 


\section{Results}

\section{1. "Pentad" ethno-system analysis}

The interaction of ethno-systems and geosystems generates new integral territorial formations -- ethno-geosystems. The constituent elements of regional EHS can be considered from the point of view of the genesis and development of ethnosystems (ethnic properties) and geosystems (landscape properties and features of environmental management), as well as their interactions and integration.

The geosystem side of the analysis is a basis for the study. The geographical approach to the study of ethnic communities identifies the systemic spatial patterns of evolution. There are dozens of these systemic units. In particular, M. Ragulina proposed culturallandscape systems based on the specifics of the original ethno-cultural landscapes using the example of the Evenki, Tofalars, Buryats, ethno-systems provided by I. Smooth, systems of ethnic nature management by T. Krasovskaya. [3, 11, 10, 13].

According to the study, there is a Turkic-Slavic ethno-contact zone formed in the forest-steppe of the Southern Trans-Ural during the last five hundred years. This ethnocontact zone serves as a combined ethno-geological system. Modern Russian nationalization institutes correlate with Tatars forming the Southern Trans-Ural ethno-contact zone with local ethno-geological systems.

Ethno-geologic systems considered stable ethnic communities of people that are formed during the territory joint and the maternal landscapes development and its components (management of natural resources, economic management and community living).

The maternal landscape serves as an enclosing basis of the system, and organization is based on the process of implementing management of natural resources within ethnogenesis. This is the most significant example of the ethnos, nature (environment) and human culture interaction, especially in polyethnic and ethno-contact regions.

An ethno-geologic system can be considered both as an institute of interelements (ethnic communities, social groups), and intracomponent (family, community, etc.), as well as external influences. The priorities of the influence of these relations at different times in the system will change, the interaction becomes possible, because they are interdependent and show a certain hierarchy (fig. 1).

Management of natural resources is an effective mechanism for the process of ethnogenesis, especially at its initial stage, when forms of natural management (fishing, 
nomadic cattle breeding, etc.) cause the local genesis of the ethnocultural processes of different ethnic groups.

Thus, ethno-geologic systems (EGS) become integral formations -- the result of the "interaction" of ethno-geological systems and geosystems in a certain territory (the maternal landscape of an ethnic group), characterized by specific natural-historical and spatial-temporal forms management of natural resources organization.

Management of natural resources is the main system-forming process in the formation of ethno-geologic systems.

The main focus of the study -- the landscape structure of the Kurgan territory -- serves as a great example of the previous thesis. The forest-steppe landscapes occupy over $90 \%$ of the Kurgan territory (geomes of the northern and southern forest-steppe), the geomes of the southern subtaiga and the prickly steppe take another small part of the territory.

Thus, the ethno-geologic system is integral valid object, reflecting the whole complex of ethnos interactions with its living environment (parent landscape). Note that the term living environment or maternal landscape of an ethnos most fully conveys the genetic characteristics of an ethnic community. The term as the ethnic community's natural component is also widespread often in the literature.

Here comes a pentad of ethno-system analysis: (1) factors (external conditions) -- (2) components (internal conditions) -- (3) excitatory processes (information movement) -- (4) actions (technologies) -- (5) result (emerging ethno-geosystems). Therefore, it is important to analyze the relations, the quantitative and qualitative streamlining, to identify the point of interethnic communication, mostly the management of natural resources and socio-ethnic relations.

\subsection{The structural ethno-contact principle}

Ethnic borderless-ness deals with a number of issues as single cross-cutting contact, the Turks and Slavs development institutions, the common institutional environment, the determination of the territorial spatial movement by government (permanent internal colonization of Russia to the East). The development of ethnicity this way has become a reason for the subsequent coexistence, complementarity and long-term ethnic integration based on joint environmental management and economic development of the territory. The main ground of the formation was structural, institutional, and territorial unity --- common institutions of contact, namely: 
- the similarity of the military-state system (the imperial traditions among the Russians and the Golden Horde -- among the Tatars);

- Orthodoxy and Islam as the basis of state ideology;

- the special role of the territorial factor (the Tatars -- drifting, the Russians -incremental);

- a similar settling factor (urban settlements among the Russians and Tatars became the nucleus crystallization of ethnicity);

- the lack of ethnic self-organization in the social structure;

- low standard of living.

Thus, the analysis of common institutions of formation and co-evolution in the process of joint environmental and economic management of Turks and Russians leads to the principle of structural ethno-contact.

\subsection{The South Trans-Ural ethno-contact zone was distinguished by strong convection and melting of ethnicity}

The natural boundaries have been changing: threshold ethnicities were absorbed. For example, Russian-Bashkir, or "repressed" -- for Kalmyks and Dzungars. The following types of ethno-geological units were formed in the Southern Trans-Urals: integrated Turkic-Slavic ethno-contact zone; ethno-geologic system of ethnic units -- Tatars, Russians, Bashkirs and sub-ethnic divisions as Cossacks, Mescheryaki. In the whole, there was a joint trend of co-evolution of ethnic groups.

\subsection{Ethnicity (ethnic archetypes) and the evolution of ethno-geologic systems}

Ethnic systems are distinguished by ethno-cultural and ethno-psychological features. The ethnic archetypes comprises the human values, norms, ideas, reactions, behavior and forms of social organization. The archetype comes into the ethnos, "objectified" in the culture and institutions of society. The adaptation strategies of ethnic groups are determined not only by the characteristics of the habitat or the level of technological development (innovations), but also by ethnic traditions and cultural values of the ethnic group. Each ethnic group forms its own representative world-image according to the mentality based on the self-organization and the cultural tradition. 


\begin{tabular}{|c|c|c|}
\hline Geological system & \multirow{5}{*}{$\begin{array}{l}\text { Ethno- } \\
\text { geological } \\
\text { system }\end{array}$} & Ethno-system \\
\hline \begin{tabular}{|l} 
Landscape \\
systems
\end{tabular} & & \begin{tabular}{|l|} 
Ethno- \\
sociological
\end{tabular} \\
\hline \multirow{2}{*}{\begin{tabular}{|l|} 
Management of \\
natural \\
resources \\
systems
\end{tabular}} & & systems \\
\hline & & $\begin{array}{l}\text { Ethno- } \\
\text { psychological } \\
\text { systems }\end{array}$ \\
\hline Sub-systems & & Sub-systems \\
\hline
\end{tabular}

Figure 1: The structure of the ethno-geological system.

According to sociology studies on the formation of new ethnic communities by $A$. Neshchadin and N. Gorin [4] the new ethnos bears in the collective unconscious idea about the archetypes of the main ethnic groups. The ethnic archetypes play an important role of occupying the given natural-geographical area and adapting the new ethnos to the natural conditions. Thus, referring to the analysis of frequency of vowels in the ancient Russian texts, Russian ethnicity emerged during the Mongolian military expansion in the 13--14th centuries and its interaction with the East Slavic and FinnoUgric ethnic groups.

Ethnicity is considered as a set of spatially localized models of an ethnos adaptation and its values and archetypes. The features of archetypes (of collective unconscious) and its features determine the ethnic constants. The preservation of ethnic constants identifies the ethnicity phenomenon.

The evolution of ethno-geological system is a process of change and complication of the spatial and temporal organization within innovations. Innovations are primarily associated with new technologies of natural resources management.

According to the bifurcation (the choice of the environmental management strategies) there are ethno-constants and attractors of ethnic cultural constants in ethnogeosystems which cause the choice of relevant development method. The balance of the ethno-geological system is determined by the degree of the development proportionality of the subsystems functional blocks. The idea of the neighborhood culture as an important factor (in particular, environmental and economic management) gives a reasom to consider the search for ways of dialogue and the possibilities of peaceful coexistence in the Southern Trans-Ural ethno-geological systems. 


\subsection{And the last, evolution -- the ethno-geological complexity led to the formation of civilized chronotopes.}

The territorial features of the Russian state formation associates with an intense relocation of the population to the East. This region can be attributed to the special Russian -- local civilization of Siberians [8].

Here are closely intertwined traditions of different ethnic communities in dynamic and mobile ethno-political, geopolitical and sociocultural space. The borders constantly float and become transparent, which is irrelevant to the steppe territories. Thus, there is an idea of the civilization chronotope of Siberians.

The influence of the natural environment on civilization and its territorial expansion is mainly important in the early stages of the ethnic groups historical development. Reflecting this process causes the relatively new concept -- "chronotope". According to the research by E. Yu. Kolbovsky, a chronotope should be understood as a complex of ethnopolitical conditions of the epoch, cultural substance of non-material order, stylistics of the space development, based on the complex of socio-economic and culturalethnographic factors [12].

There is a correlation based on the study: ethno-geological system -- local ethnic chronotope -- spatial mosaic of the system development of ethno-contact zones -formation of civilization chronotopes (Siberians). They are considered in the civilizational "arrow of time" as formed ethno-cultural landscapes of the territory. They are based on the imposition of 3 units: the physical-geographical matrix of the territory (landscapes), geopolitical (administrative-territorial) and cultural. Geopolitical conditions form a certain field of "nodes and lines" of tension inside the space.

The territory examined from a historical-geographical perspective is a zone of the Ural, Turkic Siberian, Paleo-Asian and Central Asian ethnic groups interaction (different ethno-geological systems and chronotopes).

Thus, historically and geographically there is a certain hierarchy of the territorial development of South-Western Siberia [15].

Hence within the idea of a Siberians common civilization chronotope it is possible to distinguish local chronotopes in the territory of the forest steppe Trans-Ural and South-Western Siberia:

- South Siberian Turkic-Mongolian taiga hunters and steppe nomad (from the time of the first people in the 13th century $B C$ to the 15th century $A D$ ). 
- Russian military colonization chronotope (16--17th centuries). The situation in the Trans-Urals changed radically in the late16th century when Kazan, Astrakhan and Siberian Khanate in Russia was invaded. Splits, constant strife and wars between nomadic tribes made allowed the Russians to colonize these lands. The access to the Russian state of Siberia was determined mainly by military-strategic factors. Southwestern Siberia became part of the Russian state after the defeat of the military forces of Kuchum by Yermak in 1581.

According to V. Rasputin, the accession of the territory of Siberia to the Russian state was the most important historic event after the Tatar yoke and before Peter the Great [14]. The Russian state was a considered significant among the Tatar and Ostyak population of the Siberian Khanate.

- South Siberian Türkic-Slavic Agricultural and Ural Mining (18--19th centuries):

The era of Russian colonization and population's agrarian culture of the region were relevant to the agricultural and pastoral development. There were formed zones of permanent population (lake-river configuration of settlement) in the Trans-Urals. Cossack settlements of border lines (Ostrog, Sloboda): Tobolsk (1587), Berezov (1593), Tara (1594), Shadrinsk become the central places for the development of the territory and the consolidation of Russians. He suggested an idea of homeland being reflected in the ethnicity and population. And so Siberia was to be joint to Russian state and its national features, people and the culture made the Siberia the way it is nowadays [14].

- Soviet agrarian-industrial and industrial-agrarian corresponds to the commercialindustrial, agrarian-industrial and industrial-agrarian stages of development.

- Eurasian -- post-industrial (21th centuries). Market reforms of the 90s: territorial and social compression of space: reduction of the network and population size of settlements, depopulation.

As the territory of Siberia is situated on the border of Europe and Asia it impacts on the qualitative communication, flexibility, tolerance, cultural mix, crystallization of one's own. The intercultural synthesis of the Siberian with the representatives of Eurasia opens up new development opportunities. The population of Siberia retains its ethnic and regional identity and unity despite all the tragic challenges of the 20th century (wars and revolutions). This is a real bridge, in the literal and figurative sense, between Europe and Asia.

Siberian civilization considers a geopolitical priority unit with its geographical and socio-cultural integrity. 


\section{Conclusion}

Thus, the ethno-system concept reveals the patterns of the ethno-social and territorial organization of society. The analysis was by based on the concept suggested by $D$. Klimov on the ethno-systems of the Kalmyk people and the Utah Indian tribe of the USA, the Cossacks [10].

To sum the findings up, the article provides research perspectives of ethno-geological system: the further development of the provisions on the dynamics and structure, types of systems (valid, invalid, stable and unstable, etc.); stability assessment parameters (mobile equilibrium, relative stability, traditional and innovative type); selection of boundaries and hierarchy.

The article suggests to continue the study of the quantitative parameters of the ethnogeological system stability within the theory of nonlinear dynamics (synergetics) and co-evolution. Another perspective study is put forward on the analysis of the systemic potential of the ethno-geology, particularly, quantitative and qualitative assessments, the implementation of different types of potentials.

Thus, the article objects the negative parameters of the sociocultural dimension proposed by D. Nikolayenko (such as cause of environmental crises, consistent assimilation of the foreign population, dominant language spread, large-scale economic sabotage). On the contrary, the research revealed the ideas supporting co-evolution and integration of ethnic groups based on the common development of the territory.

\section{References}

[1] Alekseev, V.P. (1989). Historical anthropology and ethnogenesis. Moscow: Science, $445 \mathrm{p}$.

[2] Baklanov, P.Ya. (2017). Territorial socio-economic systems in regional development. Proceedings of the Russian Academy of Sciences. Geographical series, no. 4, pp. 7--16,

[3] Gladkiy, I.Yu. (2006). Geographical foundations of ethnic ecology. PhD dissertation/master's thesis. St. Petersburg, 45 p.

[4] Gorin, N.I. (2011). Modernization of Russia: a Territorial Dimension. St. Petersburg: Aletheia, $217 \mathrm{p}$.

[5] Gumilyov, L.N. (2002). Ethnosfera: the history of people and the history of nature, ser.: Milestones of history. St. Petersburg: Kristall Publishing House LLC, 576 p. 
[6] Zavyalova, O.G. (2004). Nature management and development: ethno-system analysis (using the example of the Southern Trans-Urals). Tyumen: Publishing House Tyum. state University, $212 \mathrm{p}$.

[7] Zavyalova, O.G. (2018). Civilization chronotopes of Siberians (on the example of South-Western Siberia). Proceedings of the international scientific conference "Current trends in spatial development and priorities of social geography" in the framework of the IX Annual Scientific Assembly of the Association of Russian Social Geographers, p. 164--169. Retrieved from: https://elibrary.ru/item.asp?id=35309093

[8] Kaznacheev, V.P. et al. (2000). Problems of the Sphinx of the XXI century. Survival of the population of Russia. Novosibirsk: Science, $232 \mathrm{p}$.

[9] Klein, L.S. (2009). Dispute about the Vikings. St. Petersburg: Eurasia, 312 p.

[10] Klimov, D.S. (2007). The dynamics and sustainable development of ethnogeosystems (by the example of the ethno-geosystems of the Kalmyk people of Russia and the Indian tribe of the United States). PhD dissertation thesis. Kaluga, $22 \mathrm{p}$.

[11] Krasovskaya, T.M. (2005). Nature Management of the North of Russia: Socio-Cultural and Ecological-Economic Analysis. PhD dissertation thesis. Moscow, 41 p.

[12] Kolbovsky, E.Yu. (2008). Landscape Planning. Moscow: ITS “Academy", 336 p.

[13] Ragulina, M.V. (2005). Cultural geography: theories, methods, regional synthesis. $\mathrm{PhD}$ dissertation thesis. Irkutsk, $40 \mathrm{p}$.

[14] Rasputin V.G., (2015). We still have Russia: Essays, essays, articles, speeches, conversations. Moscow: Institute of Russian Civilization, 1200 p.

[15] Tales of Southwestern Siberia: the evolution of the spatial structures of society from the XV and. until now. (2009). PhD dissertation thesis. Moscow, $37 \mathrm{p}$.

[16] Sharygin, M.D. (2003). Territorial social systems (regional and local levels of organization and management). Perm: PGU Publishing House, 260 p.

[17] Huntington, S. (2008). Who are we? Challenges of American National Identity. Moscow: AST, 314 p.

[18] Bright, W. 1986. Book Notice on Ethnologue. Language, p. 162: 98.

[19] Huntington, S.Ph. (1996). The Clash of Civilizations. 